\title{
Using Internet resources in a research methods course
}

\author{
ELLEN F. ROSEN \\ College of William and Mary, Williamsburg, Virginia \\ and \\ LINDA C. PETTY \\ Hampton University, Hampton, Virginia
}

\begin{abstract}
Internet resources (a WWW home page, a Unix-based Listserv discussion list, and e-mail) were used to supplement traditional materials in a research methods course. The course also included word processing and computerized data analysis, and the student version of MEL was used as a research simulator. A computer usage survey was administered at the beginning and end of the semester. Analysis of the survey results indicated that students were more positive in their attitudes about computers as a helpful tool for psychologists at the end of the course than at the beginning. They did not show an increased appreciation for the usefulness of Internet and e-mail, however, which is probably the result of the text-based Internet browser and the slowness of the e-mail system used.
\end{abstract}

Noam (1995) states that the university must change in order to survive. He asserts that universities have served the traditional function of repositories of knowledge, meeting places for scholars, and transmitters of information, but that cheaper and more efficient means of doing these things electronically are now becoming available. Universities, if they are to continue to exist, must change to meet new needs. Traditional classes which simply transfer information no longer need be delivered in an expensive residential setting; such a setting is only necessary for contact-intensive courses (courses involving the development of social skills). These changes are already underway in psychology and are proving to be cost effective. This electronic exchange of information is a drastic change from the traditional uses of computing in psychology courses: word processing and data analysis taught primarily in statistics and research methods courses (Couch \& Stoloff, 1989). As a consequence of the explosion in access to information made possible through modern technology, the role of course instructor will be radically transformed. In the near future, individual instructors who refuse to make use of these information capabilities through lack of vision or lack of knowledge will find that their instructional skills are dated and obsolete.

Schreter (1995) proposes an alternative to the traditional model. In this alternative teaching model, the instructor inputs information (lecture notes, transparencies, explanation, etc.) into a computer database, and

The authors wish to thank James R. Rettig of Swem Library for his help. Additionally, we thank the two teaching assistants: Carla Messenger and Karen A. Smith. Correspondence concerning this article should be addressed to E. F. Rosen, Department of Psychology, College of William and Mary, Williamsburg, VA $23187-8795$ (e-mail: efrose@facstaff.wm.edu). students access this database directly at will. This is an updated version of the current model, which uses textbooks and the library reserve room. The current mode is a very slowly changing, relatively static information repository. The advent of the Internet, with general access and relatively easy printing tools, has allowed this model to become dynamic, interactive, and responsive to student need. This new model eliminates the need for physical proximity. Proximity of student and teacher is no longer required for there to be an efficient and effective exchange of information such as pictures, sound, and video, as well as text.

Takle and Taber (1995) point out that such an interactive database system allows students to self-customize the course to match their own learning style and learning rate. As a bonus, they found that students who completed their course reported that they intended to continue to participate electronically. Hypermedia, such as that available on the Web, is the solution to the problem of individual differences in learning style through its multiple paths from one learning point to another and through its use of multiple types of media (Ayersman \& von Minden, 1995). Until recently, Internet usage was often limited to text-based materials only. However, with the development of the World-Wide Web, faster personal computers, and Internet browsers such as Netscape, multiple media and hypertext have become widely available.

It is also possible to have an ongoing discussion using e-mail and a program such as the UNIX-based LISTSERV. Leege (1996) describes an e-mail discussion group component in an introductory biology class. Students were assigned to a 10-member discussion group with the requirement that each student post two messages per week to the list related to the discussion topic. Every student was required to be discussion leader one week and 
summarize the on-line discussion for that week. Thus, even a continuing, reactive discussion to class activities does not require physical proximity in time or space.

In this paper, we report on a course in which a database model was implemented along with an e-mailbased discussion list to broaden and personalize class interaction. The class resources were also enlarged through the participation of a college librarian. More traditional computer usage was part of this course as well, including word processing (WordPerfect for Windows), data analysis (SPSS for Windows), and research simulations (the Student version of MEL; St. James, Schneider, \& Hinds, 1992). Students' views of the usefulness of these tools were assessed at the beginning and end of the course to measure any changes that might have resulted from these experiences.

\section{COURSE DEVELOPMENT}

The course database available to the students included a Web page for the course which contained pointers to useful items for psychology students and supplementary course materials. The Web page was maintained under the library home page and was accessible from any Internet access point. The material in the Web page consisted primarily of links to other sites. A sampling of relevant links is given in Table 1. The addresses for the sites mentioned in the text are included in this table. These links were found by using search engines that are available on the Web at no cost, such as Lycos and Alta Vista. Search words included terms such as methods in behavioral research, psychology laboratory, and so forth. Other links were obtained by linking to already existing

Table 1

Some Useful Internet Sites for Psychology

\begin{tabular}{|c|c|c|}
\hline Name & Address (URL) & Content \\
\hline Lycos & http://www.lycos.com & Internet search engine \\
\hline Alta Vista & http://altavista.digital.com & Internet search engine \\
\hline The Psych Web & http://www.gasou.edu/psychweb/psychweb.htm & $\begin{array}{l}\text { Psychology-related information, lists of links, tip sheets, } \\
\text { copies of other sites }\end{array}$ \\
\hline Psych Sites & http://www.unipissing.ca/psyc/info.htm & $\begin{array}{l}\text { A listing of informational sources on the Web by general } \\
\text { area of psychology }\end{array}$ \\
\hline $\begin{array}{l}\text { Psychology } \\
\text { Jumping Stand }\end{array}$ & http://www.indiana.edu:80/ iuepsyc/PsycJump.html & $\begin{array}{l}\text { A compendium of links to Web sources arranged by topic } \\
\text { and by course, including a course in research methods }\end{array}$ \\
\hline Bill Trochim & http://trochim.human.cornell.edu/ & $\begin{array}{l}\text { Evaluation of Web sites, concept mapping, on-line simula- } \\
\text { tions, research methods, and an on-line textbook on evalu- } \\
\text { ation and tutorials by Trochim's students (http://trochim. } \\
\text { human.cornell.edu/tutorial/tutorial.htm) }\end{array}$ \\
\hline The beeHive & http://arts.uwaterloo.ca/ bee/remotepsych.html & $\begin{array}{l}\text { An annotated list of psychology-related links by date of } \\
\text { announcement }\end{array}$ \\
\hline Athatasca University & http://server.bmod.athabascau.ca/html/aupr/psycres.htm & A list of psychology resources \\
\hline Gleitman & http://www.wwnorton.com/norton/basic.html & Supplementary materials by topic \\
\hline Morris & http://ajax.prenhall.com/ bookbind/pubbooks/morris/ & Supplementary materials by topic \\
\hline ACA /Research & http://cavern.uark.edu/comminfo/www/methods.html & A list of other sites \\
\hline Psychology Links & http://www.ctc.edu/ -tlink.psychlink.html & A list of links by topic with a brief annotation \\
\hline CTl Centre & http://www.york.ac.uk/inst/ctipsych & $\begin{array}{l}\text { A center in the United Kingdom to facilitate the use of } \\
\text { computers in teaching psychology: a very large resource }\end{array}$ \\
\hline Virtual Lab & http://gaia.stcloud.msus.edu/virtuallab/ & $\begin{array}{l}\text { Links to interactive and noninteractive demos, tutorials, } \\
\text { and other virtual laboratories }\end{array}$ \\
\hline University of Michigan & http://www.umich.edu/ psydept/Links & List of psychology-related sites \\
\hline Allyn \& Bacon & http://www.abacon.com/psych/psychhot.html & List of sites by topic area \\
\hline Cozby's Methods & http://methods.fullerton.edu/ & Supplementary materials for Cozby's methods text \\
\hline Lecture Hall & http $/ /$ wwwhost.cc.utexas.edu/world/lecture/psy/ & List of online courses in psychology \\
\hline APA PsychNET & http://www.apa.org & American Psychological Association home page \\
\hline APS & http:/www.hanover.edu/psyc/APS/aps.html & American Psychological Society home page \\
\hline SCiP & http $/ /$ www.lafayette.edu/allanr/scip.html & Society for Computers in Psychology home page \\
\hline SPSS & http:/www.spss.com & $\begin{array}{l}\text { Statistical packages, other resources for statistics on the } \\
\text { Web and some data sets available for downloading }\end{array}$ \\
\hline PST & http://www.pstnet.com & $\begin{array}{l}\text { Demo of MEL, a few links, MEL add-ons, and some } \\
\text { patches }\end{array}$ \\
\hline Netscape Corporation & http:/www.netscape.com & $\begin{array}{l}\text { Source of Netscape Navigator and additional software } \\
\text { (plug-ins) necessary for browsing }\end{array}$ \\
\hline Asymetrix Corporation & http://www.asymetrix.com & Demos of ToolBook programs \\
\hline Psychonomic Society & http://www.sig.net/ psysoc/home.htm & Psychonomic Society home page \\
\hline
\end{tabular}


Web resources for psychology, such as the Psychology Jumping Stand. Following links provided by pages is a good way to find relevant materials. A third method for gaining links is to ask students to contribute. One possibility is to institute a scavenger hunt with a prize for some number of previously unencountered relevant links. One caution, however, is that careful evaluation must be made, since there is no guarantee that a knowledgeable person has posted the material presented on the site. With Web resources, a Web master may be anyone from a highly recognized professional to a young child. It is especially important to emphasize the need for critical evaluation on the part of student users. Some guidelines for acceptance can be an affiliation with a recognized institution (a university or professional organization); authorship by a well-known person; a recommendation by a journal or other colleague; and, of course, close scrutiny by the user and/or knowledgeable colleagues. On the Web, there are no official editors and/or reviewers.

Materials are also available through the Web from college textbook publishers. For example, supplementary materials are available for Gleitman's introductory psychology book and for Morris's study guide. With greater and greater ease of access to the Web, such textbook materials will probably grow in an exponential fashion. Some journals also have Web sites.

In addition to a traditional textbook (Goodwin, 1995) and style manual (APA, 1994), students also had access to the instructor's lecture notes, along with a few supplementary exercises in the form of a computer-based course handbook (see Rosen \& Petty, 1996) available in the psychology computer laboratory and on two computer stations in the college library. The program allowed students to print out copies of the lecture notes. The version of programming language used, ToolBook 3.0, did not link to the Web, but the new version, Instructor II, permits access by a Web browser such as Netscape Navigator 3.0. With a browser, a modem, and an Internet provider, either local or national, Internet resources can be accessed from any location. The provider will make software available for connection to the system over the phone lines. Many educational institutions have installed a network system with direct Internet access. In this case, all necessary software will already be available.

The laboratory section of the course used the student version of MEL (Psychology Software Tools). SPSS for Windows was used for data analysis, and WordPerfect for Windows for APA style write-ups. The former was available in two campus personal computer laboratories, and WordPerfect was available in all campus computer laboratories. A copy of the course schedule is reproduced in Table 2. Students were given a hard copy of the course syllabus on the first day of class. It was also included in the computer-based course handbook. The laboratory sections met in the computer lab.

Students were required to contribute to the class discussion list. The discussion list used the UNIX LISTSERV protocol. The librarian was the list owner. Each week the instructor posed a question related to that week's lectures. Students earned points toward their final grade for their contributions. The discussion list was monitored by the librarian, the instructor, and two graduate students. The instructor could point out interesting ideas during the week, pose follow-up questions, keep the group on task, and at the end of the week collate the comments, add her own conclusions, and mail the summary to the list along with the next week's question. Table 3 presents excerpts from one week's discussion.

\section{COURSE EVALUATION}

\section{Participants and Procedure}

Participants in this study were the 18 students enrolled in one section of Research Methods at William and Mary during the spring semester, 1996. Data were available for only 17 of these students. Students ranged in age from 19 to 21 years and were $65 \%$ European American. Women comprised $71 \%$ of the class. This course was taught by the first author with the assistance of two graduate students. Eighty-two percent of the students were psychology majors; the course is part of the required sequence for the major. The students had already taken an intro-

Table 2

Abbreviated Course Schedule

\begin{tabular}{|c|c|c|}
\hline Topics & Homework & Laboratory \\
\hline \multicolumn{3}{|l|}{ Philosophy of science } \\
\hline Writing an APA style paper & APA style write-up of an APA paper & Introduction to computer usage, e-mail review, and WordPerfect \\
\hline Electronic \& print media materials & Scavenger hunt & Introduction to the independent project \\
\hline Ethics in research & Independent research topic ( 5 refs.) & Writing an ethics proposal \\
\hline \multicolumn{3}{|l|}{ Developing a hypothesis } \\
\hline Measurement \& data & Data set analysis & SPSS for Windows \\
\hline Experimental research & MEL worksheet & MEL: The blind spot in vision \\
\hline Validity and control issues & APA write-up & MEL: Scanning short-term memory \\
\hline Experimental design & MEL worksheet & MEL: Impression formation and plans for "Stupid Rat Trick" \\
\hline Psychological testing & MEL worksheet \& ethics proposal & MEL: Personality \\
\hline Applied research & MEL worksheet & MEL: Telephone system \\
\hline Small $n$ designs & Daily $\log \&$ video & Begin rat training \& introduction of rat trick to working with animals \\
\hline Other techniques & Observation summaries & Observation of behavior \\
\hline
\end{tabular}


Table 3

Sample Selections From One Week's Discussion Summary

The topic of the week was:

"Let's talk about control issues and validity this week. Which do you think is more important to worry about: internal or external validity? In other words, when I design an experiment to answer a particular question/test a hypothesis, should I concern myself more about experimental control issues (e.g., experimenter bias, order effects, etc.) or about issues pertaining to generalizability (e.g., subjects, situations, etc.). Can we come up with some decision rules or descriptors about which is more important when?"

And these are the responses some of you sent:

1. I think that internal validity is more relevant and should be monitored more closely. The environmental conditions and subject behavior should be well regulated, but internal biases and experiment technicalities are more significant to the outcome of the study. For one thing, the behavior of subjects is not something that is easy to control whereas experimenter bias is somewhat easier to control. Overall internal validity seems more contingent to the success of the experiment.

3. I think external validity is most important since that determines whether or not results may be generalized to other groups. If a study's conclusions cannot be extended what good is the study? Although internal validity seems important too because if one has methodological flaws then the results are void anyway. Perhaps trying to say one type of validity is more important than the other is like asking the chicken and egg question--it just can't be answered

5. The question of which is more important, external or internal validity, is a tough one. Both are essential to psychological testing and experimentation. If asked to quickly pick one, I would pick internal because it's completely useless to be conducting an experiment when the results won't be valid. But then, as I think about it, I change my mind to external because psychology as a science is based on experimentation where the results must be able to be generalized and apply to other populations, places, times, etc. I'm sorry but I really can't make up my mind. Both are ESSENTIAL. The argument is circular.

My concluding comment:

The consensus of our discussion this week is that internal and external validity are both important. Most felt that if one had to yield to the other external validity has to yield to internal validity needs.

ductory statistics course or were taking it at the same time (all of the students had already completed three or more psychology classes, and the majority of the students were second semester sophomores). The students completed a survey on the first and next to last days of class about their computer and Internet experiences. The survey was constructed from the questionnaire used in an earlier study (Rosen \& Petty, 1995).

\section{First Day Results}

Because prior computer experience is one of the best predictors of acceptance of the usefulness of computer skills (Rosen \& Petty, 1995), some background measures were taken. On the average, the students were not very computer experienced (3.4, with a standard deviation of
1.7 on a scale of $1=$ strong disagreement to $7=$ strong agreement). Using the same response scale, students reported some knowledge of e-mail $(M=5.5, S D=1.9)$ and not much about using either the Internet $(M=3.6$, $S D=2.0)$ or a database such as PsychLit $(M=2.1, S D$ $=1.5$ ), or about how to join and participate in a discussion list $(M=2, S D=1.4)$ before starting the course. Thus, these students were not computer literate, apart from their familiarity with e-mail at the outset of the course.

\section{Course Effects}

The pre- and posttest means were compared with paired-sample $t$ tests using SPSS for Windows; these results are summarized in Table 4 . There was a significant

Table 4

Some Statistics from Pre- and Posttesting on Course Impact on Computer Attitudes

\begin{tabular}{|c|c|c|c|c|c|c|c|c|}
\hline & r & & Pretes & & & & Signi & nce \\
\hline & Question & $N$ & $M$ & $S D$ & $M$ & $S D$ & $t$ & $p$ \\
\hline 1. & Computers have relevance to my life. & 16 & 4.6 & 1.7 & 5.1 & 1.3 & 1.45 & n.s. \\
\hline 2. & My feelings about computers are very positive. & 16 & 3.9 & 1.8 & 4.7 & 1.6 & 2.24 & .04 \\
\hline 3. & I want to learn as many computer applications as possible. & 16 & 5.2 & 1.8 & 4.3 & 1.7 & -1.85 & n.s. \\
\hline 4. & Computers can help me gain a better understanding of the subject matter. & 16 & 5.0 & 1.6 & 5.1 & 1.0 & 0.36 & n.s. \\
\hline 5. & Computers helped me do my work for this course. & 16 & & & 5.8 & 1.5 & & \\
\hline 6. & If I were teaching this course I would not include any computer usage. & 15 & 2.9 & 1.5 & 1.9 & 1.1 & -2.35 & .034 \\
\hline 7. & I was computer anxious prior to this course. & 15 & 4.3 & 2.1 & 4.4 & 2.1 & 0.37 & n.s. \\
\hline 8. & I am more computer anxious now than at the beginning of the course. & 16 & & & 2.1 & 1.2 & & \\
\hline 9. & I am inept with any mechanical device. & 16 & 3.4 & 1.7 & 2.8 & 1.6 & -1.38 & n.s. \\
\hline 10. & I am skillful with computer programs. & 15 & 3.3 & 1.6 & 3.8 & 1.3 & 1.33 & n.s. \\
\hline 11. & I like to study and work alone. & 16 & 5.4 & 1.4 & 5.7 & 1.2 & 0.86 & n.s. \\
\hline 12. & I am anxious about taking math courses. & 16 & 2.8 & 2.1 & 5.6 & 1.6 & 2.14 & .05 \\
\hline & I must see the relevance of something in order to be able to understand it. & 16 & 4.7 & 2.0 & 4.3 & 1.7 & -0.68 & n.s. \\
\hline 14. & I can learn things easily on my own. & 16 & 4.8 & 1.1 & 5.2 & 0.8 & 1.9 & n.s. \\
\hline 15. & I think the Internet is very helpful. & 16 & 5.2 & 1.4 & 5.2 & 1.3 & 0.24 & n.s. \\
\hline 16. & I think email is very useful. & 16 & 5.8 & 1.1 & 6.4 & 0.8 & 1.06 & n.s. \\
\hline 17. & I think on-line databases are very useful. & 13 & 4.6 & 1.0 & 6.4 & 0.9 & 4.15 & .001 \\
\hline 18. & Computer discussion is very helpful. & 12 & 4.2 & 0.4 & 4.1 & 1.5 & -0.19 & n.s. \\
\hline
\end{tabular}


increase in positive feelings toward computers. On the rating scale, a " 4 " is the midpoint or balance point between the disagreement (negative response or "not me") and agreement ("yes, me") sides of the scale. So the change from 3.9 to 4.7 represents a cross from the negative to the positive side of the scale. Another significant finding was that students indicated much stronger disagreement on the posttest than on the pretest with the statement that computer usage should not be required in the class.

They strongly agreed that they knew how to use e-mail at the end of the course $(M=6.7, S D=.6)$, although they mildly agreed with not wanting to have to use email for written assignments $(M=3.8, S D=1.8)$. They generally agreed that they knew how to use the Internet by the end of the course $(M=4.9, S D=1.7)$, although they were ambivalent about whether or not they wanted to be required to use it. Also, the students reported by the end of the course that they knew how to use on-line databases such as PsychLit $(M=6.4, S D=.6)$ and felt that they were very useful and that they knew how to participate in a discussion $(M=6.3, S D=.6)$, but they did not think that this was any more helpful than they did at the beginning of the class.

There was a large, significant, positive correlation between reported computer experience at the beginning of the course and a positive attitude toward computers after the course ( $r=.57, n=16, p=.023$ ). Students who reported that the discussion list was useful at the end of the course also reported that they found the computer helpful in doing their work for the course $(r=.50, n=16$, $p=.047)$, and those who reported that e-mail was useful at the end of the course also tended to be the same students who found on-line databases useful at the end of the course $(r=.65, n=16, p=.007)$.

\section{CONCLUDING COMMENTS}

Over the semester, the students developed an appreciation of how helpful computers can be in psychology. Failure to find an increased appreciation of the usefulness of e-mail and the Internet may have resulted from the level of technology available to the students at this time. Student access to the Web was generally only available in the form of Lynx, a text-only browser. The students reported that they did learn how to use this textbased Internet access and e-mail, but they did not like it. The key to the burgeoning popularity of the Internet has been graphics and hypertext. The Web page for this course was designed so that it could be read from a textonly browser, which greatly reduced its attractiveness to students. Students would rather read text in a book or on a handout than on a computer screen (Takle, 1995).

The discussion list was e-mail based. To participate in the discussion, students had to send e-mail to the LISTSERV address. To read the messages, students had to collect their e-mail. This, they reported, could be a very painful process, lasting up to $30 \mathrm{~min}$. The system used the DOS version of Pegasus Mail on a slow network with a data line that did not always work. As a result, students were reluctant to collect their mail or send mail and avoided using it as much as possible.

There is some confusion about the effectiveness of computer mediated communication (CMC). According to Hightower and Sayeed (1995), CMC is more likely to produce biased discussion (a tendency of group members to introduce only some of the information that they know about the subject at hand.) They assert that biased discussion leads the group to discuss only the most popular or first presented position in the group. Such biased discussion can lead a group working on a task to come up with an inadequate solution to a problem. Good, efficient problem-solving requires the simultaneous evaluation of all possible solutions (Rosen \& Petty, 1989). In this class, however, because the discussion came after the in-class presentation and was prompted by the instructor, the biased nature of the CMC discussion was a useful feature, allowing for a directed discussion while all students were actively involved with the topic that the instructor put forth. Thus, the structure provided in this course for CMC took advantage of the biased-discussion phenomenon. Clearly, the CMC discussion must be structured.

From the instructor's perspective, incorporating a discussion list into the class is very useful. Class interaction and communication between students and between students and the instructor is available outside the classroom. Additional thoughts, handouts, and data from the laboratory exercises can be sent to every student at any hour of the day and from any location. Every student, even the quiet and shy ones, must participate in the discussion, and they can do it at any time from any location and discussion is not dominated by a few extroverted individuals. E-mail provides a way to communicate privately with a student without singling the student out in the class. E-mail also provides access to the instructor in a way that is less threatening for most students and not limited to office hours. Thus, ironically, the computer, which has been predicted to dehumanize and isolate individuals in our society, actually provides increased ease and comfort in two-way communication between students and faculty and, therefore, facilitates active learning.

\section{REFERENCES}

American Psychological Association (1994). APA style manual (4th ed.). Washington, DC: Author.

AyERSMAN, D. J., \& vON MINDEN, A. (1995). Individual differences, computers, and instruction. Computers in Human Behavior, 11, 371-390.

Couch, J. V., \& SToloff, M. L. (1989). A national survey of microcomputer use by academic psychologists. Teaching of Psychology, 16, 145-147.

Goopwin, C. J. (1995), Research in psychology: Methods and design. New York: Wiley.

HightOWER, R., \& SAYEED, L. (1995). The impact of computer-mediated communication systems on biased group discussion. Computers in Human Behavior, 11, 33-44.

LEEGE, L. M. (1996). Technology in teaching: Email discussion groups [On-line]. Available http://wxweb.msu.edu/ taprog/email.htm 
NoAm, E. M. (1995). Electronics and the dim future of the university. Science, 270, 247-249.

Rosen, E. F., \& PetTy, L. C. (1989). Teaching human sexuality using guided design. Journal of Sex Education \& Therapy, 15, 121-126.

Rosen, E. F., \& PETTY, L. C. (1995). The Internet and sexuality education: Tapping into the wild side. Behavior Research Methods, Instruments, \& Computers, 27, 281-284.

Rosen, E. F., \& PetTy, L. C. (1996). Selecting an appropriate multimedia authoring language. Behavior Research Methods, Instruments, \& Computers, 28, 286-290.

St. JAMES, J., SChNejder, W., \& Hinds, K. (1992). MEL lab: Experiments in perception, cognition, social psychology and human factors. Pittsburgh: Psychology Software Tools.
SCHRETER, Z. (1995). Using the Internet for teaching purposes [On line]. Available http://info.utas.edu.au/psychology/tws/iws.htm

TAKLE, E. S. (1995). Taking the plunge [On-line]. Available http://www. physics.iastate.edu//gcp/teaching/plunge.html

TAKLE, E. S., \& TABER, M. R. (1995). Teaching on the Internet: Experience with a course on global change [On-line]. Available http:// www.physics.iastate.edu//gcp/teaching/bioethics.html

(Manuscript received September 30, 1996; revision accepted for publication December 20, 1996.) 